\title{
ESR Studies of Mn(II) Binding to Carboxymethyl and Phosphorylated Chitins in Aqueous Solutions
}

\author{
Akihiro Tsutsumi, Shigemoto SaSAJIma, Teruo Hideshima, \\ Norio NisHI, ${ }^{*}$ Shin-Ichiro NishIMURA, ${ }^{*}$ \\ and Seiichi TOKURA* \\ Department of Applied Physics, Faculty of Engineering, \\ Hokkaido University, Sapporo 060, Japan \\ * Department of Polymer Science, Faculty of Science, \\ Hokkaido University, Sapporo 060 Japan
}

(Received January 6, 1986)

\begin{abstract}
KEY WORDS Carboxymethyl Chitin / Phosphorylated Chitin $\downarrow$ Manganese Ions / Complex / ESR /
\end{abstract}

Chitin which is widely distributed as a supporting polysaccharide of crustacea is insoluble in general organic solvents as a result of its rigid, crystalline structure supported by hydrogen bonds between hydroxyl groups and acetamide groups of $\mathrm{N}$-acetylglucosamine residues. ${ }^{1}$ Recently, chemical modifications of chitin have been investigated and samples soluble in water or organic solvents have been obtained. ${ }^{2-4}$ Using these chitin derivatives, it has been possible to study the chemical and physical properties of chitin in detail. ${ }^{5-7}$ Among them, 6-O-(carboxymethyl)chitin (CM-Chitin) and 3,6-O-(phosphorylated)chitin (P-Chitin) have been found to form complexes with various metal ions containing $\mathrm{Mn}(\mathrm{II})^{4.7}$ In this paper, electron spin resonance (ESR) was applied to investigate the binding of $\mathrm{Mn}(\mathrm{II})$ ions to $\mathrm{CM}$ - and P-Chitin in aqueous solutions.

Preparations of CM- and P-Chitin were made with the procedures reported previously. ${ }^{3.4}$ Figure 1 illustrates the chemical structure of these chitin derivatives. The degree of substitution (D.S.) was defined as the average number of substituted groups to a repeated unit. D.S. of CM-Chitin was 0.7 for the sub- stitution group $\mathrm{R}_{1}$ and that of $\mathrm{P}$-Chitin 1.4 for $R_{1}$ and $R_{2}$. PH of the aqueous solutions was adjusted with a small amount of concentrated aqueous solutions of $\mathrm{HCl}$ and $\mathrm{NaOH}$, and measured by a Horiba-F8L pH meter. All of the solutions contained $0.1 \mathrm{M} \mathrm{NaCl}$. To the solutions of CM- and P-Chitin, an aqueous solution of $\mathrm{MnCl}_{2}$ was added to investigate the interactions of $\mathrm{Mn}$ (II).

ESR measurements were made on the aqueous solutions containing $50 \mathrm{mM}$ chitin derivatives and $10-15 \mathrm{mM} \mathrm{Mn}(\mathrm{II})$. ESR spectra of $\mathrm{Mn}(\mathrm{II})$ ions were taken at $30^{\circ} \mathrm{C}$ with a JEOL JES-1XG at a microwave frequency of 9.24

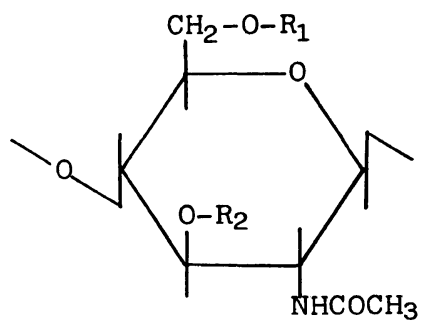

Figure 1. Chemical structures of chitin and chitin derivatives, chitin $\left(R_{1}=H, R_{2}=H\right)$, carboxymethyl chitin $\left(\mathrm{R}_{1}=\mathrm{CH}_{2} \mathrm{COOH}, \mathrm{R}_{2}=\mathrm{H}\right)$, and phosphorylated chitin $\left(\mathrm{R}_{1}=\mathrm{PO}_{3} \mathrm{H}_{2}, \mathrm{R}_{2}=\mathrm{PO}_{3} \mathrm{H}_{2}\right)$. 


\section{A. Tsutsumi et al.}

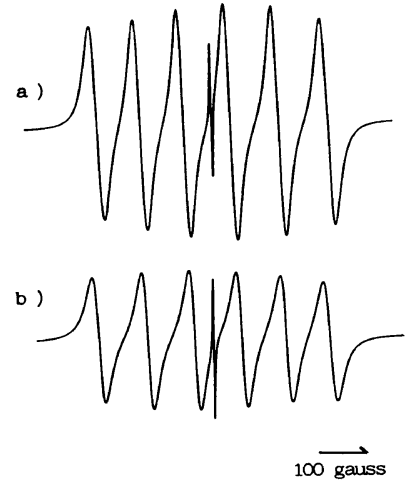

Figure 2. ESR spectra of $\mathrm{Mn}$ (II). a) $50 \mathrm{mM} \mathrm{Mn}$ (II) aqueous solution containing $0.1 \mathrm{M} \mathrm{NaCl}$ at $\mathrm{pH} 5.5$; b) with coexistence of $50 \mathrm{mM} \mathrm{CM}-\mathrm{Chitin}$.

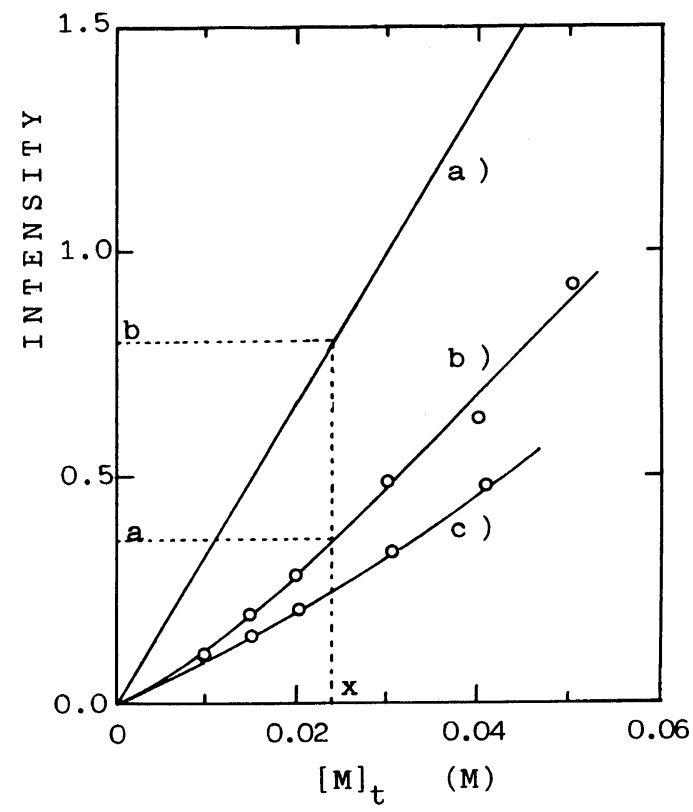

Figure 3. ESR signal intensity of $\mathrm{Mn}(\mathrm{II})$ vs. $[\mathrm{M}]_{\mathrm{t}}$ for aqueous $\mathrm{Mn}(\mathrm{II})$ solutions containing $0.1 \mathrm{M} \mathrm{NaCl}$ at $\mathrm{pH}$ 5.5. a) $[\mathrm{Ch}]=0$; b) $[\mathrm{Ch}]=50 \mathrm{mM}$ CM-Chitin; c) $[\mathrm{Ch}]=50 \mathrm{mM}$ P-Chitin.

$\mathrm{GHz}$ with a power $1 \mathrm{~mW}$ which did not cause saturation effects. The $100 \mathrm{kHz}$ field modulation width was 6.3 gauss. The aqueous solution was placed in a $0.75 \mathrm{~mm}$ i.d. quartz capillary tube. The signal intensity was defined as the average peak height of the derivative six lines of $\mathrm{Mn}(\mathrm{II})$ and was expressed in units of the spectral peak height of diphenylpicrylhydrazyl (DPPH) as the external reference.

Figure 2 shows the ESR spectra for a $50 \mathrm{mM}$ $\mathrm{Mn}(\mathrm{II})$ aqueous solution (upper spectrum) and for the same solution but containing $50 \mathrm{mM}$ CM-Chitin. The central sharp singlet is due to an extremely small amount of powdered DP$\mathrm{PH}$ as the external reference. It has been reported that the ESR signal of $\mathrm{Mn}(\mathrm{II})$ disappears when it binds to a macromolecule. ${ }^{8,9}$ In Figure 2, it is seen clearly that the intensity of $\mathrm{Mn}$ (II) signal is reduced by the addition of CM-Chitin. This fact indicates that parts of $\mathrm{Mn}(\mathrm{II})$ ions were bound to CM-Chitin. Similar results were also obtained for the aqueous solution of P-Chitin. The measurements of the intensity, therefore, give the amounts of manganese ions bound to the chitin derivatives.

The molar concentration of free, $[\mathrm{M}]_{\mathrm{f}}$, and bound, $[\mathrm{M}]_{\mathrm{b}}$, manganese ions were estimated from the ESR spectra. Figure 3 shows the plots of the intensities against the total $\mathrm{Mn}$ (II) ion concentration $[\mathrm{M}]_{\mathrm{t}}$ for the aqueous $\mathrm{Mn}(\mathrm{II})$ solution without and with chitin derivatives. $[\mathrm{M}]_{\mathrm{f}}$ and $[\mathrm{M}]_{\mathrm{b}}$ were obtained using the relations

$$
\begin{aligned}
& {[\mathrm{M}]_{\mathrm{f}}=x(a / b)} \\
& {[\mathrm{M}]_{\mathrm{b}}=x-[\mathrm{M}]_{\mathrm{f}}}
\end{aligned}
$$

where $a, b$, and $x$ are defined in Figure 3. The dissociation constant $K_{\mathrm{d}}$ for the $\mathrm{Mn}(\mathrm{II})$ chitin derivative complex and the number of binding sites per residue $n$ were graphically determined using the relation ${ }^{10.11}$

$$
[\mathrm{Ch}] /[\mathrm{M}]_{\mathrm{b}}=\left(K_{\mathrm{d}} / n\right)\left(1 /[\mathrm{M}]_{\mathrm{f}}\right)+1 / n
$$

where $[\mathrm{Ch}]$ is the total concentration of the chitin derivatives. Figure 4 shows a plot of $[\mathrm{Ch}] /[\mathrm{M}]_{\mathrm{b}}$ against $1 /[\mathrm{M}]_{\mathrm{f}}$ at $[\mathrm{Ch}]=50 \mathrm{mM}$ and $\mathrm{pH}$ 5.5. The slope and intersect give $K_{\mathrm{d}}=1.1$ $\times 10^{-2} \mathrm{M}$ and $n=0.6$, and $K_{\mathrm{d}}=2.4 \times 10^{-2} \mathrm{M}$ and $n=1.4$ for CM- and P-Chitin, respectively. It is noted that the values of $n$ are nearly the same as those of D.S. (degree of substitution) for the two chitin derivatives employed, 


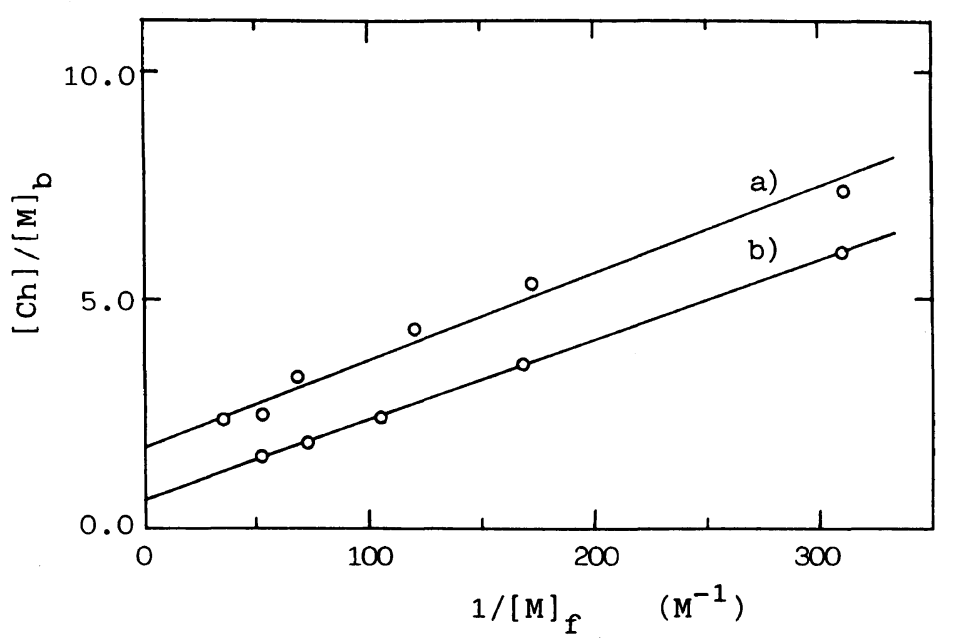

Figure 4. Plots of $[\mathrm{Ch}] /[\mathrm{M}]_{\mathrm{b}}$ vs. $1 /[\mathrm{M}]_{\mathrm{f}}$ for $\mathrm{Mn}(\mathrm{II})$-chitin derivatives complex in aqueous solutions at $[\mathrm{Ch}]=50 \mathrm{mM}$ and $\mathrm{pH}$ 5.5. a) $\mathrm{Mn}(\mathrm{II})-\mathrm{CM}-\mathrm{Chitin}$; b) Mn(II)-P-Chitin.

suggesting that $\mathrm{Mn}$ (II) mainly binds to the substituted carboxymethyl and phosphoryl groups. These results indicate that the binding of $\mathrm{Mn}(\mathrm{II})$ to chitin derivatives is fairly strong. More detailed studies involving other metal ions are in progress.

Acknowledgements. This work was supported by a Grant-in-Aid for the Science Research from the Ministry of Education, Science, and Culture of Japan.

\section{REFERENCES}

1. F. G. Pearson, R. H. Marchessault, and C. Y. Liang, J. Polym. Sci., 43, 101 (1960).

2. N. Nishi, H. Ohnuma, S. Nishimura, O. Somorin, and S. Tokura, Polym. J., 14, 919 (1982).

3. S. Tokura, N. Nishi, A. Tsutsumi, and O. Somorin,
Polym. J., 15, 485 (1983).

4. N. Nishi, S. Nishimura, A. Ebina, A. Tsutsumi, S. Tokura, Int. J. Biol. Macromol., 6, 53 (1984).

5. S. Tokura, J. Yoshida, N. Nishi, and T. Hiraoki, Polym. J., 14, 527 (1982).

6. S. Tokura, S. Nishimura, and N. Nishi, Polym. J., 15, 597 (1983).

7. S. Tokura, N. Nishi, S. Nishimura, Y. Ikeuchi, I. Azuma, and K. Nishimura, in "Chitin, Chitosan and Related Enzymes," P. Zikakis Ed., Academic Press, Inc., London, 1984, p 303.

8. G. H. Reed and M. Cohn, J. Biol. Chem., 245, 662 (1970).

9. K. Hikichi, T. Hiraoki, and N. Ohta, Polym. J., 16, 437 (1984).

10. T. R. Hughes, and I. M. Klotz, "Methods of Biochemical Analysis," Vol. 3, D. Glick Ed., Interscience Publisher, New York, N. Y., 1956, p 265.

11. H. Jouve, H. Jouve, E. Melgar, and B. Lizarranga, J. Biol. Chem., 250, 6631 (1975). 